then perforce we shall have to limit our ambitions and discover more economical methods of attaining our ends. As yet we are not within sight of such a crisis.

C'o-ordination is a Necessary Constituent of Irogress. $C_{p}$ to this point $I$ have been discussing the manifestations of progress as seen in the Harley Street quarters of our greater cities, in our medical schools and hospitals, and in our subsidized laboratories. In all three quarters we find medical men pressing forwards in search of new sources of knowledge, and as they press becoming subdivided more and more into separate groups. We have, in these instances, been studying only one of the factors of medical progress; there is another which Spencer perceived was equally inevitable. Specialization, if it worked unchecked, would tend to break up our medical forces and dissipate their strength in confusion. Hence we find, in the progress of our profession, just as in the evolution of the earlier inimal organizations, there come into play certain unifying influences, exerted by a crude form of nerrous system. An astute student of the evolution of medicine, if he had visited London in 1880 , would have perceived that this nerve centre had already come into being in the form of a Department of State, situated in Whitehall-the Local Government Board. He would have found London already divided into fifty-two districts-each with a medical officer of health-controlled more or less indirectly by the nervous rentre in Whitehall. All England, Wales; and Scotland had then become so divided, and a multitude of medical men, most of whom, while still continuing to attend to their patients, served also as members of a health armr, and carried out a policy "formulated or suggested in Whitehall.

\section{The Process of Integration.}

Unification or integration is just as necessary an ingredient of "progress" as specialization or separation. The influences which tend to bring about the unification of our medical army, like most of the inventions which alter medical practice, arise not inside our medical ranks but outside them. Before the middle of the nineteenth century it became evident to British statesmen that the country could not drift along exposing itself to plagues and pests, to contaminated water and adulterated fooks, to overflowing cesspools and to drains which led nowhere. Government began tentatively by calling into being a new kind of medical specialist - the health officer. Presently it was found to be necessary to co-ordinate the activities of the men so enrolled. Eren in 1880 this brain, then represented by the Local Government Board in Whitehall, was a small and simply fashioned organ. The deliberative and executive areas of its cortex were composed of laymen ; eleven medical officers entered into its texture and were relegated entirely to the sensory or recipient areas. Ther were advisory in function at the most. No doubt the reformers who placed all our public health Acts on the Statute Book had to fight hard and long; they fought with head and heart, and deserved their victory; but, as they gained it, it never occurred to them that they were being impelled by force of circumstances, and were unconscious exponents of a scheme of crolution. Health reformation was initiated outside the ranks of our profession, but it introduced into our ranks the first step towards their unification.

IVe are the Slaves of Circumstance.

What I am seeking to make clear is that in all our advances we are the slaves of circumstance rather than masters of our fate. Y'ou may ask: Does not the Ministry of Health, which succeeded the Local Government Board in 1919, determine the direction in which we shat adrance? Iately I listened to a speech which was booadcast by an able member of Sir George Newman's staff-Dr. T. Carnwath. In this speech the policy of the Ministry of Health was outlined. The Ministry watches how health measures, recently sanctioned by Parliament, work out in practice. Defects become apparent, the Ministry studies how they can be mended. Local authorities may apply for a special bill to meet some local need; if leave is granted, the Ministry notes the effects. If benefits accrue, then steps are taken to extend them to the whole country. The Ministry does not create its opportunities; it waits until they come, and then utilizes them for an "advance.". Sir George Newman and Sir Walter Fletcher have both to wait for their opportunities. They wait patiently for them, and then when they occur apply their genius in utilizing them for the improvement of national health.

\section{Progress implies an increasing Integration.}

Every step taken hr Parliament leads towards a more perfect unification of our British medical army-in which 54,000 recruits are now enrolled. We are far enough awas from the angry discussions which arose in our ranks when Mr. Lloyil George successfully carried the National Insurance Act of 1911 to take a philomonhical view of what then happened. We see now that it was the inevitable that happened; it was but another turn in the screw of that evolutionars movement which tends towards the unification-the integration-of Medicine. It was a continuation of that "policy" of the nineteenth century which broadened the franchise to its present limits, gare us compulsory education, established the medical inspection of schools, and more recently gave services for the welfare of mothors and babies. The Local Government Act, which brings the staff. of our hospitals more directly under a ceitral authority, is but another turn of the same erolutionary wheel. The art of healing in its modern derelopment is going steadily through the stages which transformed a brood of discrete independent protozon into the co-ordinated complexity of cells which form the body of a living animal.

\section{The Irar of Erolution.}

In this lecture $I$ have been applying a law-the law of animal erolution-to the complex affairs of modern medicine. Given human nature as it is-a nature which demands, and ever will demand, that the poor must and shall have access, so far as health is concerned, to all the privileges the rich can buy, that at all costs suffering must be reliered-then medical progress must go on and follow the path already chosen. Further progress consists, in our modern interpretátion, of an ever-increasing degree of specialization, and in an crer-increasing degree of coordination or unification. We cannot escape State control in the long run, howerer much we may regret the loss of personal liherty which is thereby entailed. What I would especially lay stress on is that medicine is not so free to choose its path into the future as most of us think it is. We may mould circumstances to our wills on some occasions, but in most we are carried along in the irresistible current of events. I do not mean we should, like fatalists, cease to strive to steer a course. Nevertheless in things medical, as in all mundane affairs, the main feature of the law of crolution is its inexorability.

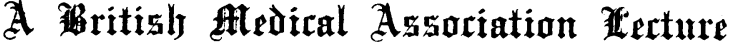
ox

\section{THE LOCALIZATION OF ABDOMINAL PAIN. \\ BY \\ V. ZACHARY COPE, M.D., M.S., F.R.C.S.,} SURGEON TO St. MARY'S hospital, padDingtiton.

Paix felt in the abdominal area may for practical purposes be divided into (a) pain arising from a pathological stimulus applied in some other part than the abdomen, and (b) pain in which the causative stimulus arises within the abdominal earity itself. The localization of the pain in the first class of case is not very difficult so long as one realizes the possibility of the source being in some more remote part. A thorough physical examination of the patient will usually detect disease of the spine or spinal cord, or throw suspicinn on to the chest, in cases where that region is to blame.

A very real difficulty may arise in those cases in which physical examination (including radiography) reveals nothing abnormal, and ret the patient arers that he has very severe pain in the abdomen. Speaking generally, such patients must be regarded as suffering from some real abdominal disorder until every means of diagnosis has been tried. Only after a failure of these and the inability to fit in the symptoms with any known clinical

$$
\text { * Given before the Leeds Division on March 6th, } 1930 .
$$


condition must one allow the term "psychogenic" to be applied. It is very easy to shirk a full examination by saying the pationt is neurasthenic. Neurasthenia covers a multitude of crrors of diagnosis; nevertheless no one doubts that some abdominal pains may have their origin in montal discase. In such cases the patient often makes much more of his pain than is warranted by his fairly good general condition, while the term "agonizing" is more frequently used to describe the pain than in the ase of those patients who have serious organic disease.

The localization of true abdominal pain is one of the most difficult problems with which the rhysician and the surgeon have to deal. The difficulties are inseparable from the anatomical configuration and the physiological interrelation of the various viscera. Anatomically the various riscera are so close one to another that the symptoms caused by disease of the one may easily be thought to emanate from another. Moreover, the mobility of certain parts of the intestine, and the way in which inflammatory or other fluid may travel quickly from one end to the other of the peritoneal space make eiror more eass.

Physiologically we are hindered in our quest by the vague diffuseness of the pain which is caused by acute visceral discase, and by the puzzling way in which a very great stimulus may cause a widespread extension or overflowing of the pain from the usual area associated with a certain visceral lesion. There is in addition a frequent confusion of reflexes -for example, pyloric spasm, which gires rise to pain of the gastric type, may be a reflex effect not only of duodenal ulcer but also of appendicitis or cholecystitis; while a painful distended colon may follow not only from colitis ?ut from acute cholecystitis. Pathological difficulties in locating pain result from the occasional occurrence of multiple lesions, either independent or interdependert. To point this moral I. am accustomed to quote a case which I saw eight ycar's ago.

A man, aged 55 , had acute abdominal pain especially in the right lumbar region. He was distended and had a great amount of free fluid in the peritoneal cavity. The liver was large and there were cardiac murmurs. He died without any operation being performed. At the necropsy the peritoneal cavity was full of pus and bile; the common bile duct was filled by large stones; there was a large hydatid cyst of the right kidney; there was aortitis with a small saccular ancursym, and the foramen ovale was patent; there was healed tubercle at both the lung apices, and the pericardium was adherent. As if this was not enough, when the intestines were opened they were found to contain a large tapeworm.

With difficulties of this kind to contend with I sometimes wonder how it is that we are able to make such a large proportion of correct or approximately correct localizations of abdominal pain.

True abdominal pains may have their origin in a pathological stimulus applied in solid or hollow viscera, the mesentery of the gut and pedicles of viscera, and the abdominal parietes. The adequate stimulus for producing pain is not the same for each of these groups. In the case of a solid riscus such as the liver, spleen, and kidney, pain is caused by acute tension of the organ consequent on congestion and oedema. Hollow viscera and tubes give rise to the sensation of pain when they are acutely passively distended, or when the muscles in their walls contract very violently. Nerve trunks in mesentery or in pedicles will produce severe pain when crushed, pulled upon, or strangled, and to a lesser degree when irritated by inflammation. As for the abdominal parietes, those parts which are sensitive respond to a variety of stimuli in the same way as does tlre skin. The parts of the peritonem and subperitoneal tissues which are supplied by the somatic nerves are particularly sensitive to touch, pressure, and irritation by various bacteria and irritating fluids.

'The solid visceia are not very sensitive to touch, though pressure may cause pain. The intestines may be cut, pinched, and otherwise manipulated without any pain so long as they are not distended, but pressure and manipulation of distended gut will always cause pain, as also will traction on the mesentery. Chronic abdominal pain indicates a persisting derangement of function or structure, which is usually traced by a combined clinical, chemical, radiological, and bacteriological examination. If sufficient time and care is taken most arses of chronic pain can be located. Tn the case of acute abdeminal pain, howerer, the clinical cxamination is perforce the most important, for momentous decisions have to be taken by the practiticner on the spot, and I desire particularly to be of assistance in cases of this nature.

Most cases of acute abdominal pain may be jut into one of two categories: those due to obstruction of some tube or outlet of a hollow viscus, and those due to inflammation of a viscus with or without involvement of the perifonem. These two classes of pain I shall consider separately. Both varieties are localized by the same aids, but the importance of the various aids varies greatly in the two cases. These aidis are:

Spontaneous local pain,

Tenderness (evoked loca! pain),

Superficial hyper'sensitive 'ess,

Pain felt at a distance (reisrled pain),

Pain in contiguous viscera.

The shifting of pain, and the

Clinical history.

Pain causec ${ }^{3}$ by obstruction of a hollow tube, preventing the outflow from a hollow viscus, may be divided into two clearly defined groups. The first is the pain due to the stoppage of a canal without any accompanying occlusion of the blood vessels. Biliary colic due to a stone stopping up the cystic or common bile duct, renal colic consequent on a small calculus becoming impacted or passing down the ureter, uterine colic due to a small polyp or blood (lot in the cavity of the uterus, intestinal colic due to anyt!ing kinking or obstructing merely the lumen of the gut, and a tubal abortion, serre as examples. In all of these the blood ressels supplying the affected part are intact. Now at the onset of any of these colies one is largaly dependent for localization upon the clinical history and the position of the referred segmental pain; in such cases as intussusception and tubal abortion the clinical history may suffice to-point accurately to the location of the pain, white in many other cases it is a most valuable help, and it is here that clinical experience may and does prove its great worth.

The position of the pain felt at a distance-referred pain -varies according to the case. In biliary colic it is commonly epigastric and right hypochondriac, and usually it is alse felt in the right subscapular region. But the pain may be referred to the left hypochondrium, and $I$ lately had a patient whose biliary pain was only felt in that position. The pain of renal colic, apart from perinephric irritation, is felt in the iliac regions, and radiates to the groin or testicle. When the renal pelvis becomes distended loin pain is felt and parietal irritation plays a greater part. Uterine colic causes pain in the lumbar and sacral region of the spine. Small-intestine colic is referred to the epigastric and umbilical regions, while that caused by the large bowel is felt chiefly in the hypogastrium. An acute!y distended bladder will irritate the parietes so that its pain is located in front; but if the distension is gradual no pain is felt anteriorly, and the patient will only complain of pain in the lumbar region.

At the onset of these colics there is usually no tenderness on deep pressure, no muscular rigidity, and only occasionally hypersensitiveness of the skin. Far from intensifying the pain, pressure will actually relieve it, and in contrast with the immobility consequent on most inflammations the patient will often turn and twist about to find relief.

An interesting referred pain is that felt in the testicle in some cases of appendicitis. It is more common with a perforated appendix, but can occur either in right or left testicle with an unperforated appendix. In some cases it may be due to a direct irritation of the nerves in the spermatic cord, but in other cases there can be little doubt that it is a referred pain, and this has made me conclude that the appendix is at least in part supplied by the tenth scoment of the cord which also supplies the testicle. Whether this is so or not the importance of the fact is clear, for the confusion of renal lesions with appendicitis is thereby made ma:e easy.

When obstructive colicky pain has continned for some hours one or both of two consequences follow: either the viscus communicating with the obstructed tube bocomes distended, or inflammation extending to the peritoneum or parietes may result. In both cases local tenderness supervenes, and this makes localization fairly casy. $A_{n}$ acutely distended gall-bladder, an acutely inflated coil of 
small intestine, and a tense pelvis of the kidney are all tender on pressure, and pain in them can be acrurately Jocated. The late Sir James Mackenzie used to teach that pain in the viscera was not actually felt in them, but was actually felt in the parietes as a referres pain; this view rannot now be maintained. Pain is re:tainly felt in the viscera, but it is not accurately located in them without the aid of the parietes. A tense or distended riscus cries out in an unknown language, which is interpreted by the parietes when palpated, the parietes indicating the site of the pain. This point can be made clearer by considering the manipulation of a distended coil when the aldomen has been opened under local anaesthesia. If the coil is outside the body the patient experiences diffuse central pain, but can give no idea of the exact position of the coil; when the coil is pressed upon through the abdominal wall he can tell the exact site of the pain. I alwars compare the function of the parietes to that of a piano lieyboard in relation to a tone-deaf person. Anvone who cannot tell the difference between one note and another can still tell what note is being played if he looks at the note which has been struck on the keyboard. The parietes is a keyboard which indicates the site of pain felt in the intestincs and other viscera.

In those parts of the intestine which have so short a mesentery that distension of the gut cluags upon the parietes pain may be more or less accurately located. Most persons have at some time or other accurately located borborrgmi in the ileo-caecal region and the iliac colon. The same spontaneous location of intestinal pain is possible when gut is adherent in the sac of an umbilical hernia; when gut is merely incarcerated it may not cause spontaneous local pain, but may be tender on pressure. How often superficial hyperaesthesia occurs from visceral irritation alone I am not prepared to state, but that such hipersensitiveness does occur without parietal irritation I am quite convinced. Its frequency is, however, so inconstant that it has very little practical ralue. I would emphasize again the point that colic in an uninflamed undistended viscus is not usually accompanied by local tenderness on pressure.

The second obstructive group comprises cases of occlusion or torsion of hollow tubes together with obstruction of the blood ressels going to the part; rolvulus and obstruction by a band serve as examples. With this group should be classed the cases of strangulation of an ovarian cyst, or of a solid viscus, since the svmptoms are somewhat similar. In all these cases the blood vessels are suddenly occluded and there is a sudden onset of pain and tenderness. The pain due to irritation of nerves in the pedicle or mesentery is diffuse and does not help in localization except as between the small and large gut, but local pressure will elicit the pain, and if the viscus is near the anterior or lateral abdominal parietes spontaneous local pain will be felt.

$A$ special case is that in which only part of the circumference of a piece of gut is strangled; here very little distension may result, and since the nerves in the mesentery are not affected the adequate stimulus for eren the visceral referred pain is absent. In these cases localization depends upon the spread of inflammation to the parietes, and if, as in some cases of femoral hernia, the related part of the parietal peritoneum is almost insensitive, localization may be very difficult. Hence the common overlooking of a Richter's hernia even when gangrenous. The stoppage of blood supply to a large portion of the bowel by a mesenteric thrombosis or embolism leads to generalized abdominal pain and tenderness froin the first. At the onset the pain may result from irregular peristalsis, but later it is accounted for by distension and peritonitis. Diagnosis may be possible, but accurate localization of the part involved may be, and generally is, out of the question.

To sum up: In the early obstructive lesions without vascular occlusion localization is effected br the clinical history, and the distribution of the rather rague visceral referred pain; later there supervenes local tenderness depending on distension or inflammation spreading to the peritoneum. With obstructive vascular lesions local tenderness is present from the first.

Passing to the second large group of cases causing acute abdominal pain, the inflammations, it is noteworthy that hacterial infection of the interior of a riscus may, and often does, cause no pain at all. There mar be little or no pain with an infection of the ducts in the liver, and sometimes even with suppuration in the branches of the portal rein. The entire absence of pain in some cases of liver abscess is well known. Infection of the renal pelvis, and of the interior of the uterus, may be practically painless. If pain is to be caused br infection of a viscus one of three things must happen: the duct (if there be one) must become obstructed so as to bring about distension: or the inflammation must spread to the parenchyma to cause oedema and tension; or the irritation must spread to the peritoneal coat and abdominal parietes. The first two possibilities have already been considered, leaving for discussion now the localization of risceral lesions by contiguous inflammation of the abdominal parietes.

The effect of irritation of the parietal peritoneum varies greatly according to whether there is a free or scanty somatic nerre supply. Trritation of those parts of the parietes which are supplied by the lower dorsal and upper lumbar spinal nerves canses local pain. tenderness on pressure, often a cousiderable reflex rigidity of muscles, and sometimes a certain amount of superficial hyperaesthesia. Inflammation of those parts which have a seanty nerre supply, or a supply derived from the srmpathetic system, gives few if any of these indications for localization. Intermediate in its demonstrativeness between these two areas comes the diaphragmatic area, which causes local pain when its periphery is inflamed, but when the main part is irritated merely demonstrates that irritation by distant pain felt in the acromio-clavicular region.

In discussing this question $I$ am accustomed to emphasize these points by dividing the abdominal lining into demonstrative and silent areas. By a demonstrative area $I$ mean one which on irritation gives rise to pain, hyperaesthesia, and muscular rigidity, which demonstrate the site of the pain. By a silent area $I$ indicate a part in which inflammation does not proroke spontaneons pain, does not give rise to cutaneons hyperaesthesia, and never causes rigidity of the parietal muscles. Pressure on an inflamed silent area may, however, cause a certain amount of pain. This broad distinction, which I propounded eight years ago, has not ret been generally adopted, but I consider it of the first importance. In the silent area inflammation may proceed with little pain and give no indication of its presence apart from the general symptoms, unless the irritiltion happens to spread either to a neighbouring viscus which may betray it, or to the demonstrative area of the parietes.

From a failure to recognize this distinction many grave mistakes in the localization of abdominal pain must result; cases of deep abdominal abscess have at some time or other proved puzzling, and escaped diagnosis because they wero in a silent area of the peritoneum. Tho best illustration of this is the inflamed pelvic appendix, which may perforate and cause local peritonitis in the pelvis without any definite localizing sigus. Such cases are not infrequentli diagnosed only when the pelvic abscess causes intestinal obstruction. This mistake is prevented hy an carly rectal examination, for local tenderness is generally to be clicited. A similar difficulty may be found in the case of an appendix which perforates behind the end of the ileum. Umbilical and inguinal hernial sacs are usually sensitire, but the femoral hernial sac is usually silent.

The clemonstrative part of the parietes localizes pain in several ways. The actual spot is tender on pressure, anrl usually gives rise to spontaneous pain. The neighbouring muscles are tender and often rigid, there may be hypeaesthesia of the skin, and contiguous viseera may be affected.

Painful rigidity of muscles almost always indicates inflammatory irritation of the underlying poritoneum, but absence of painful rigidity does not signify absence of peritonitis, for the muscles tire after it time. Rigidity is not usual in late peritonitis. Rigidity occurs not only in the lateral and anterior abdominal muscles, but also in the quadratus lumborum, psoas, and diaphragm. An inflamed appendix lying on the psoas may be localized by putting the psoas on the stretch by extending the thigh. Diaphragmatic rigidity causes immohility of the affected part of the diaphragm on respiration. Occasionally an abscess lying against the ohturator fascia mav lead to oedematous infiltration of the fascia and rigidity of the 
obturator internus; this may cause pain when the muscle is put on the stretch by inverting the thigh in the flexed position. When an inflamed area is in contact with the iliac vessels this may be demonstrated sometimes by occluring the fenoral vessels with the finger; the increased pulsation of the iliac artery causes slight pain oving to its contiguity with the parietal peritoneum.

Cutaneous hyperaesthesia is a more common accompaniment of parietal than of visceral irritation, though I cannot anree with the view that a viscero-sensory reflex does not exist. Peritonitis in the lower abdomen, whether arising from an inflamed appendix, an infected Fallopian tube, or other cause, commonly causes hyperaesthesia somewhere below the umbilicus and above Poupart's ligament; this hypersensitiveness is more common on the right side than on the left. A narrow band of hyperaesthesia is often found just above the right Poupart's ligament in cases of appendicitis, but the same band may ocrur with a perforated ulcer, and occasionally with cholecystitis, so that it is likely to be due to parietal irritation in the right iliac fossil.

Pain due to irritation of adjacent viscera may be of value in localizing lesions in the silent areas of peritoncum -thus pain in passing urine, associated with frequency, may call attention to an inflamed pelvic apjendix.

The shifting of a pain is often of value in localizing the lesion. Severe cpigastric pain followed soon by tenderness and pain in the hypogastrium indicates an upper abdominal perforation. Severe hypogastrie pain followed soon by pain at the top of the shoulder should suggest lower abdominal haemorthage. Epigastric pain followed in a few hours by definite tenderness in the right iliac fossia usually indicates appendicitis.

The third area of the abduminal parictes-namely, the diaphramatic-is the most interesting and the most neglected of the three. Inflammatory irritation of the central part of the diaphragm causes no pain which is felt locally, but it commonly leads to a not very acute pain felt in the acromio-clavicular region on the same side of the body. This pain is, of course, easily explained by the fact that the descending acromial and clavicular branches of the cervical plexus come from the same segments of the spinal cord as the phrenic nerve.

My interest in phrenic shoulder pain began in Mesopotamia during the war. I found that liver abscess was only accompanied by pain at the top of the shoulder when the abscess was threatening to penetrate the diaphragm. From a study of these cases I came to the conclusion that it was the diaphragm, and not the liver, which was the source of the referred pain. This led me to investigate cases of gallstones to see if the textbooks were correct in stating that pain was felt at the top of the shoulder in such cases. Here again I found that this shoulder pain only occurred when there was inflammatory change near the diaphragm; next $I$ found that it was a common symptom in cases of perforated ulcer of the duodenum, and from this the reneralization as to its significance was easy. Sinilar investigations were about the same time carried cut in Germany, but $I$ did not see these till my own views were formed.

The localizing value of phrenic shoulder pain is considerable, and hardly a week passes without my finding it of use; it often gives the needed clue in unravelling a difficult case. When an abdominal lesion is accompanied by pain in the supraclavicular, supraspinous, or acromial regions it will generally be found that there is inflammatory irritation of the diaphragm on the side of the pain. There is also a correspondence between the position of the irritation and the part of the shoulder to which the pain is referred-that is, irritation of the front and back of the diaphragm causes pain respectively in the clavicular and supraspinous regions. The pain is not usually severe; it is often thought by the patient to be a rheumatic pain, and may not be mentioned unless inquiry be made; occasionally, there may be accompanying hyperaesthesia. This pain must not be confused with the subscapular pain often felt with biliary colic and other lesions. At the time of its development in the early embryo the diaphragm is in the cervical region, and only later do the heart and lungs push it down to its subsequent position; the relative positions of the diaphragmatic lesion and its referred pain are better understood by imagining that the migration has not taken place. The localizing value of such pain would then appear obrious.

Phrenic shoulder pain is of localizing value in a great variety of conditions. In three out of four cases of perforated ulcer it is present at some time or other; sometimes it comes on simultaneously with the abdominal pain, but occasionally a few hours later. With perforated uleer the pain is generally felt in the right supraspinous fossa and acromial region, but it may be felt at the back of the neck. The general statement may be made that sudden severe right hypochondriac pain accompanied by collapse and by pain felt on the top of the shoulder is almost always due to a leaking duodenal ulcer. Pain here is seldom caused by cholecrstitis, and hardly ever by uncomplicated biliary colic. The legend that gatlostone colic gave rise to pain at the tip of the shoulder arose in the dars when operative confirmation of the diannosis was not forthcoming, and has been perpetuated in the usual slack manner of textbooks from generation to generation. The clinical simulation of the one condition by the other may be extremely close.

A man, aged 41, who suffered from indigestion of no definite type, was seized with sudden acute abdominal pain on September 28th, 1922, but improved a little afterwards. When I saw him, four days later, there was a tender lump at the anterior border of the liver in the region of the gall-bladder. The main feature in the case, however, was the severe pain felt all over the outer and supcrior aspect of the right delioid region. 'The patient said tho pain was so severe that he could not lie on the right arm. I thought the condition was most probably due to an inflamed gall-bladder, but at the operation 1 found between the liver and tho diaphragm an enormous collection of bilious fluid, which came from a perforation of the duodenum.

In making a wrong diagnosis here I went against my own experience that severe shoulder pain is much more often due to a perforated ulcer than to gall-bladder conditions.

Six montlys ago a, woman, aged 50, was seized with violent upper abdominal pain with collapse, and pain on top of the right shoulder. When I saw her, four hours later, she looked and felt much better, there was resistance and tenderness in the right hypochondrium, but no tenderness anywhere else in the abdomen; again I diagnosed cholecystitis with biliary colic. Four days later when I operatcd I found a recently sealed-up perforation of the duodenum, with a normal gall-bladder.

A medical friend of minc rang me up urgentiy saying he feared he had gall-stones, because he had right hypochondriac pain and pain at the tip of the shoulder. He said he thought it was gallstones because as a student he had been taugit that shoulder-tip pain meant gall-stone disease. As a malter of fact he had diaphragmatic pleurisy, and no evidence of abdominal trouble, but the case shows how erroncous teaching on this point still may be.

Phrenic shoulder pain is also of value in sudden severe intra-abdominal haemorrhage. In a young woman of childbearing age sudden collapse with hypugastic pain and pain on top of the shoulders should lead to the suspicion of a ruptured ectopic gestation.

With peritonitis of any origin top of the shoulder pain generally indicates that the infection has reached the diaphragm.

A patient who had had an operation on the rectum developed perilonitis, wlich proved rapidly fatal. The rlay before she died she complained of pains on top of the right shoulder, which puzzled those in attendance. When told of this symptom at the nceropsy I advised inspection of the top of the liver, and there, as I expected, was found a great deal of inflammatory lymph, which by its irritation of the diaphragm must have caused the pain.

Finally, attention must be directed to the important fact that even with serious advancing lesions acute pain often tends to become less acute. This may result from several factors. In the first place the stimulus may be lessened by the dilution of toxins by effused fluid, by the rupture of a distended viscus, or by the gradual localization and limitation of the lesion. Secondly, although the peripheral stimulus may be undiminished, there may be a fatigue of the reflexes which cause some of the pains. Finally, in toxic states the sensorium becomes dulled, and the patient is then no longer in a position to appreciate pain as he was in the early stages of the condition. It is often very difficult to locate the diffuse and uncertain pains of late acute abdominal disease; and the moral of that hardly needs pointing out-diagnose early. 